\title{
Potential Bias of Response Type Road Roughness Measuring Systems: Causes and Remedial Measures
}

\author{
Mohammad Mamunur Rashid* and Koji Tsunokawa
}

\author{
Department of Civil \& Environmental Engineering, Saitama University, 255 Shimo-Okubo, Sakura-Ku, Saitama-Shi \\ 338-8570, Japan
}

\begin{abstract}
Response-type road roughness measuring systems estimate pavement roughness from correlation equations. Most of these systems recommend to maintain a constant survey speed or to keep the speed within a certain range. But carrying out a survey with this speed constraint may not always be possible due to the existence of traffic control devices and heavy traffic flow. Therefore, these systems may produce a significant bias in roughness measurement because of survey speed fluctuations. The objective of this study is to develop calibration equations that eliminate the bias produced by survey speed fluctuations. A simplified regression relationship for IRI with bump integrator reading and survey speed as explanatory variables is developed using ROMDAS bump integrator. Using a case study, this study also investigates how the bias created by speed fluctuations affects roughness and demonstrates how developed calibration equations eliminate that bias.
\end{abstract}

Keywords: ROMDAS, international roughness index, calibration equation, bump integrator, speed, alternative calibration equation, conventional calibration equation.

\section{INTRODUCTION}

Road roughness is the deviation of a road surface from a true planar surface with characteristic dimensions that affect vehicle dynamics, ride quality, dynamic loads, and pavement drainage. Roughness is primarily related to serviceability, structural deficiencies and road deterioration [1]. It is one of the key indicators to evaluate road performance and condition [2]. Roughness affects safety, comfort, travel speed and vehicle operating costs $[1,3]$. Therefore, pavement condition (roughness) has been considered as one of the key factors to make a decision for further road works [4-7]. Recent literature regarding optimization of pavement maintenance strategies also addressed roughness as an important indicator that affects lifecycle costs (including road user costs and maintenance costs) of a road section [8-12]. Therefore, road agencies should be able to measure road condition (roughness) precisely, as economic evaluation of road maintenance and upgrading expenditure depends on this indicator.

At present, the most commonly used road roughness measuring index is the International Roughness Index (IRI) introduced by the World Bank [13]. The IRI is a mathematically defined as summary statistic of the longitudinal profile in the wheel paths of a traveled road surface [1,3]. Although roughness measurements are matured technologies, there are still works to be done in improving their accuracies [1]. Various types of equipments are widely used for carrying out road roughness survey. According to the accuracy and methodology used to determine IRI, they are classified into four categories. Class I devices incorporate precision profiles, Class II devices consider other profile methods, Class III

*Address correspondence to this author at the Department of Civil \& Environmental Engineering, Saitama University, 255 Shimo-Okubo, Sakura-ku, Saitama-shi 338-8570, Japan; Tel: 81803487 5254; Fax: 8148858 7374;

E-mail: masum_ait@yahoo.com devices estimate IRI from correlation equations and Class IV considers subjective ratings and uncalibrated measures [1, 14]. Response type road roughness measuring systems (RTRRMSs) belong to class III devices. As RTRRMSs estimate roughness implementing correlation equations of IRI with other variables, these systems are able to collect roughness data of a long pavement section quickly compared to many devices of Class I and Class II [15-17]. In some instances, RTRRMSs may get better results than more sophisticated Class I system, since they reflect the effects of the entire contact area of the tire with the pavement surface [1]. However, most of the RTRRMSs still have one common limitation that is restrictions in survey speed. It is essential for these systems to maintain a constant survey speed or to keep the speed within a certain range [18-20].

RTRRMSs measure the dynamic response of vehicles to the road surface by using either accelerometers or mechanical devices. Roadmaster and Roughometer are commonly used accelerometer based systems. These roughness measuring accelerometers do not work properly and hence yield unreliable results with low survey speeds. Therefore, Roadmaster as well as Roughometer recommends maintaining a survey speed higher than $40 \mathrm{~km} / \mathrm{h}$. Regarding the upper limit of speed, Roadmaster does not have any restriction but Roughometer suggests not to exceed $60 \mathrm{~km} / \mathrm{h}[19,20]$. On the other hand, Road Measurement Data Acquisition System (ROMDAS) bump integrator and Transport Research Laboratory (TRL) bump integrator are commonly used mechanical devices for carrying out roughness survey [21, 22]. Both these devices use calibration equations of IRI that is a function of bump integrator reading ${ }^{1}$. These calibration equations are normally developed for several speeds. Therefore, these systems suggest maintaining the survey speed close to one of

${ }^{1}$ Bump integrator reading is generated from the relative movement of the vehicle floor to the suspension. 
the calibration speeds [18]. Carrying out a survey by maintaining a constant speed or keeping the speed within a certain range might be possible in a free or private road. It may not always be possible to follow this speed constraint due to the existence of traffic control devices (such as signals, signs, traffic lights) and heavy traffic flows. In that case, survey speed may fluctuate that can reduce the accuracy and cause a significant bias in roughness measurements. Investigation of various RTRRMSs reveals that no system is free from speed constraint and suitable for any survey speed. Thus bias in roughness measurement that can be caused by not maintaining specified speeds may be a common problem for many RTRRMSs. Therefore, there is a strong need to eliminate this bias and allow speed fluctuations for these roughness measuring systems.

The objective of this study is to develop calibration equations that eliminate the bias produced by survey speed fluctuations. In order to do this, a simplified regression relationship for IRI with bump integrator reading and survey speed as explanatory variables is developed using ROMDAS bump integrator as a case. Moreover, this study investigates how the bias created by speed fluctuations affects roughness, and demonstrates how developed calibration equations eliminate that bias using a case study.

This paper is organized as follows. Section 2 discusses methodology. Section 3 applies the proposed approach in case and discusses the results. Finally, section 4 concludes the paper.

\section{METHODOLOGY}

This section includes a brief review of IRI estimating procedure used in ROMDAS, observation of the bias due to speed constraint and improvement of the calibration equations. Fig. (1) depicts the procedure of IRI estimation using ROMDAS bump integrator.

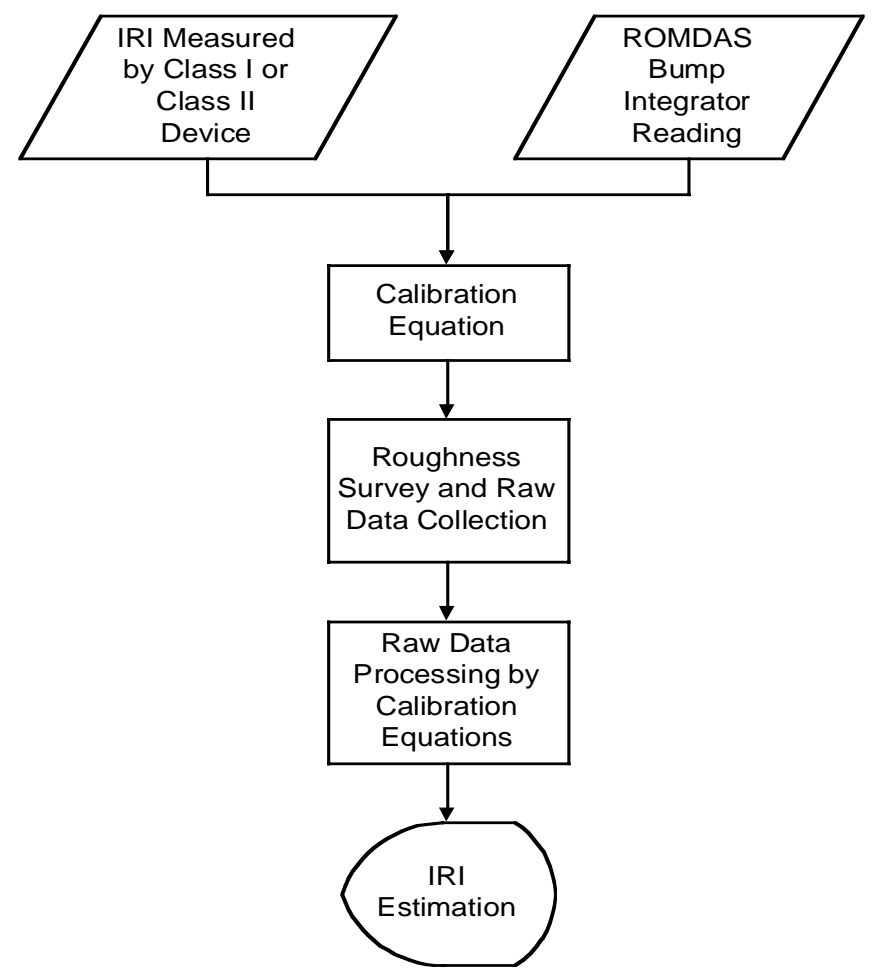

Fig. (1). Procedure of IRI Estimation used in ROMDAS.
This bump integrator records the relative movement of the vehicle floor to the suspension during the operation and produces 1 pulse per $0.8 \mathrm{~mm}$ suspension movement [21, 22]. Therefore, the output of bump integrator is generated in terms of count per $\mathrm{km}$, which is the accumulation of the number of pulses in one kilometer. In order to develop a correlation equation of bump integrator reading with IRI, at first roughness of several sections along the wheel paths is precisely measured. Class I or Class II devices can be used to do this. In this study, Z-250 reference profiler is used for this purpose [23]. Vehicle installed with ROMDAS bump integrator is then operated following the same wheel paths to record the bump integrator readings. Bump integrator readings and IRIs found in different sections are then used for developing regression equations which are called calibration equation in this system. As bump integrator reading is sensitive to the vehicle speed, different calibration equations are produced for different vehicle speeds. Calibration equations forward the system to the actual roughness survey. Bump integrator readings are only collected during the survey. These raw data (bump Integrator readings) are processed using the earlier developed calibration equations and converted into IRI.

\subsection{Conventional Calibration Equation}

The calibration process is based on roughness measured by Class I or Class II devices and data generated by bump integrator. Two bump integrators connected with left and right wheels are used in this study. These integrators are calibrated separately using the procedure mentioned earlier. Three sections of different roughness are used for calibration. Each of the sections is 100 meters in length. Roughness Indices of these sections found by Z-250 reference profilers are shown in Table $\mathbf{1 .}$

Table 1. Roughness of Different Sections.

\begin{tabular}{|c|c|c|c|}
\hline Section ID & Description ${ }^{2}$ & $\begin{array}{c}\text { IRI, } \mathbf{m} / \mathbf{k m} \\
\text { (Left) }^{\mathbf{3}}\end{array}$ & $\begin{array}{c}\text { IRI, } \mathbf{m} / \mathbf{k m} \\
\text { (Right) }^{\mathbf{4}}\end{array}$ \\
\hline \hline 1 & Medium Rough & 3.95 & 2.25 \\
\hline 2 & Smooth & 2.03 & 1.45 \\
\hline 3 & Rough & 4.49 & 3.63 \\
\hline
\end{tabular}

For developing calibration equations, bump integrators are operated in three sections where IRIs are determined by Z-250 profiler (mentioned in Table 1). Three speeds, 30 $\mathrm{km} / \mathrm{h}, 45 \mathrm{~km} / \mathrm{h}$ and $60 \mathrm{~km} / \mathrm{h}$, are used for the calibration. For every speed and section, five bump integrator readings are taken and average of them is considered to generate more precise calibration equations. Regression analysis of the mean of bump integrator counts and IRIs measured by Z-250 reference profiler produces roughness calibration equations. Figs. (2) and (3) depict the output of this analysis for bump integrator 1 (Left Wheel) and bump integrator 2 (Right Wheel) respectively. Calibration equations obtained for both bump integrators are as follows.

\footnotetext{
${ }^{2}$ This is found by visual inspection.

${ }^{3}$ This is the roughness along the left wheel path.

${ }^{4}$ This is the roughness along the right wheel path.
} 
Bump Integrator 1:

$$
\begin{aligned}
& \text { IRI }= 0.0013 \mathrm{x}+0.4122(30 \mathrm{~km} / \mathrm{h}) \\
&(1.66) \quad(0.21) \\
& {\left[\mathrm{R}^{2}=0.7347, \text { Adjusted } \mathrm{R}^{2}=0.4693\right] } \\
& \mathrm{IRI}= 0.0008 \mathrm{x}+1.4783(45 \mathrm{~km} / \mathrm{h}) \\
&(2.75) \quad(1.81) \\
& {\left[\mathrm{R}^{2}=0.8835, \text { Adjusted } \mathrm{R}^{2}=0.7670\right] } \\
& \text { IRI }= 0.0008 \mathrm{x}+1.1289(60 \mathrm{~km} / \mathrm{h}) \\
&(2.01) \quad(0.89) \\
& {\left[\mathrm{R}^{2}=0.8016, \text { Adjusted } \mathrm{R}^{2}=0.6033\right] } \\
& \text { Bump } \text { Integrator } 2: \\
& \text { IRI }=0.0015 \mathrm{x}+1.1239(30 \mathrm{~km} / \mathrm{h}) \\
&(39.84) \quad(28.03) \\
& {\left[\mathrm{R}^{2}=0.9994, \text { Adjusted } \mathrm{R}^{2}=0.9987\right] } \\
& \text { IRI }= 0.0012 \mathrm{x}+1.1529(45 \mathrm{~km} / \mathrm{h}) \\
&(82.65) \quad(60.56) \\
& {\left[\mathrm{R}^{2}=0.9999, \text { Adjusted } \mathrm{R}^{2}=0.9997\right] } \\
& \text { IRI }= 0.0009 \mathrm{x}+1.0895(60 \mathrm{~km} / \mathrm{h}) \\
&(436.98) \quad(292.80) \\
& {\left[\mathrm{R}^{2}=1, \text { Adjusted } \mathrm{R}^{2}=1\right] }
\end{aligned}
$$

where $\mathrm{x}$ is bump integrator reading (count $/ \mathrm{km}$ ) and numbers in the parentheses are t-statistics of respective parameters. Linear relationships were considered in this calibration process. However, if linear specification does not fit well, other forms of relationships can also be applied. Fitness of equations $(4,5,6)$ representing the bump integrator 2 is very high. On the other hand, fitness of equations $(1,2,3)$ representing the bump integrator 1 is comparatively lower. Calibration data shows inconsistency, especially for vehicle with speeds $30 \mathrm{~km} / \mathrm{h}$ and $45 \mathrm{~km} / \mathrm{h}$ which intersect each other (Fig. 2). This may be explained by the fact that the bump integrator 1 (Left Wheel) is on curb side close to the shoulder picking up many irregularities. Fitness of this calibration equa- tion might be improved by increasing the number of runs.

Calibration equations developed for different speeds are used to estimate roughness in ROMDAS even if the speed is not maintained properly. For instance, calibration equations are developed in this study for three speeds; $30 \mathrm{~km} / \mathrm{h}, 45$ $\mathrm{km} / \mathrm{h}$ and $60 \mathrm{~km} / \mathrm{h}$. Therefore, the equations of $60 \mathrm{~km} / \mathrm{h}(3$, 6) are applied for the survey speed range of $52.5 \mathrm{~km} / \mathrm{h}$ (mid point of $45 \mathrm{~km} / \mathrm{h}$ and $60 \mathrm{~km} / \mathrm{h}$ ) and above when bump integrator readings are converted into IRIs. Similarly, equations of $45 \mathrm{~km} / \mathrm{h}(2,5)$ and $30 \mathrm{~km} / \mathrm{h}(1,4)$ are used for the speed ranges of $37.5 \mathrm{~km} / \mathrm{h}$ (mid point of $30 \mathrm{~km} / \mathrm{h}$ and $45 \mathrm{~km} / \mathrm{h}$ ) to $52.5 \mathrm{~km} / \mathrm{h}$ and 0 to $37.5 \mathrm{~km} / \mathrm{h}$ respectively. So, ROMDAS applies only one equation for a range of survey speed. As bump integrator is sensitive to vehicle speed and calibration equation is developed for specific speeds, hence ROMDAS restricts the survey speed to be maintained close to the calibration speeds. But, maintaining constant speed during actual survey may not always be possible as discussed earlier. Under this circumstance, it is better to develop roughness calibration equation as a function of bump integrator reading and vehicle speed to eliminate the constraint of maintaining a constant speed.

\subsection{Development of Alternative Calibration Equation that Eliminates Speed Constraint}

Alternative specification of calibration equation is developed in this study which generates a calibration equation using bump integrator reading and survey speed as explanatory variables of IRI. Since this equation includes vehicle speed as an explanatory variable of IRI, it eliminates the constraint of maintaining the survey speed within a certain range or at a constant speed during the roughness measurements.

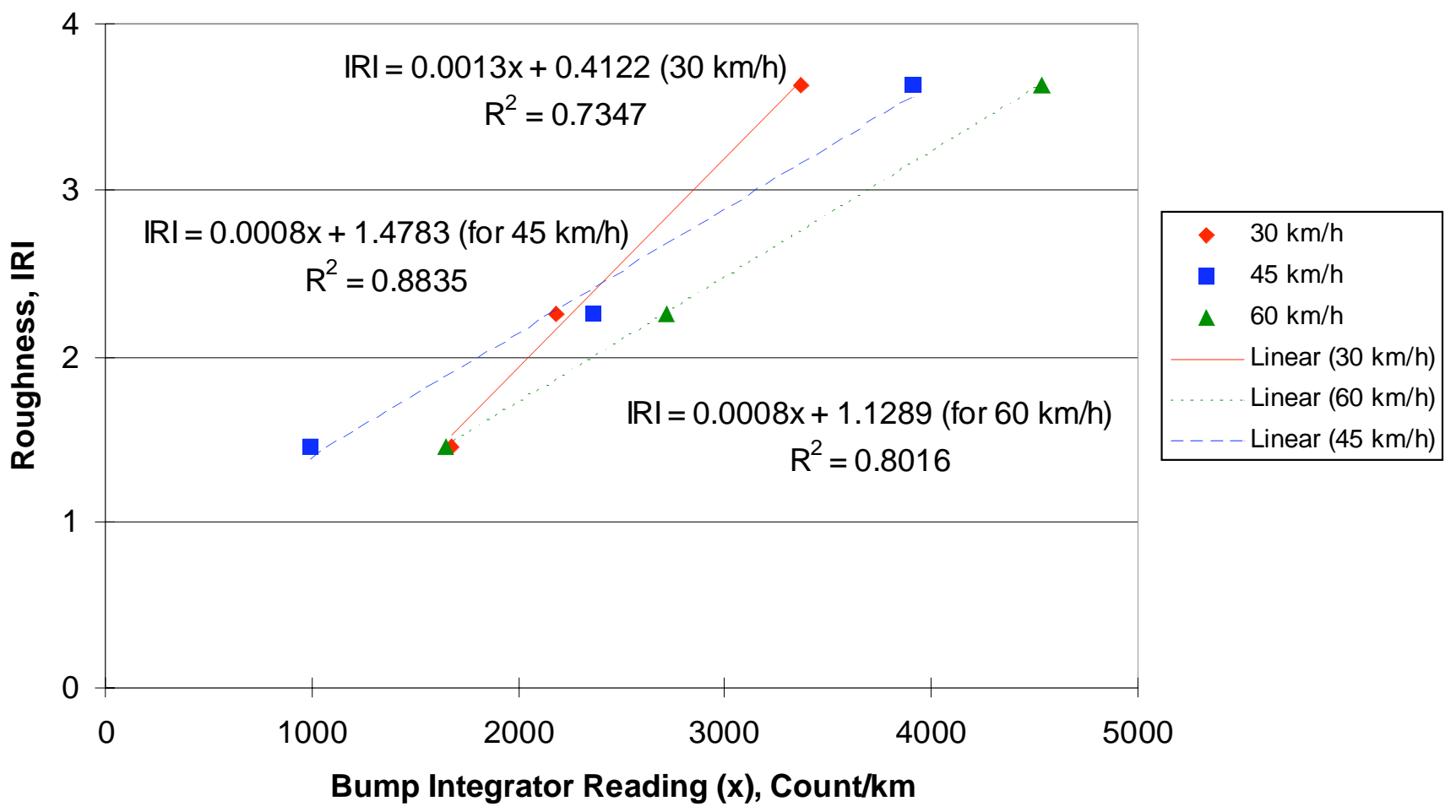

Fig. (2). Roughness Calibration Equation for Bump Integrator 1. 


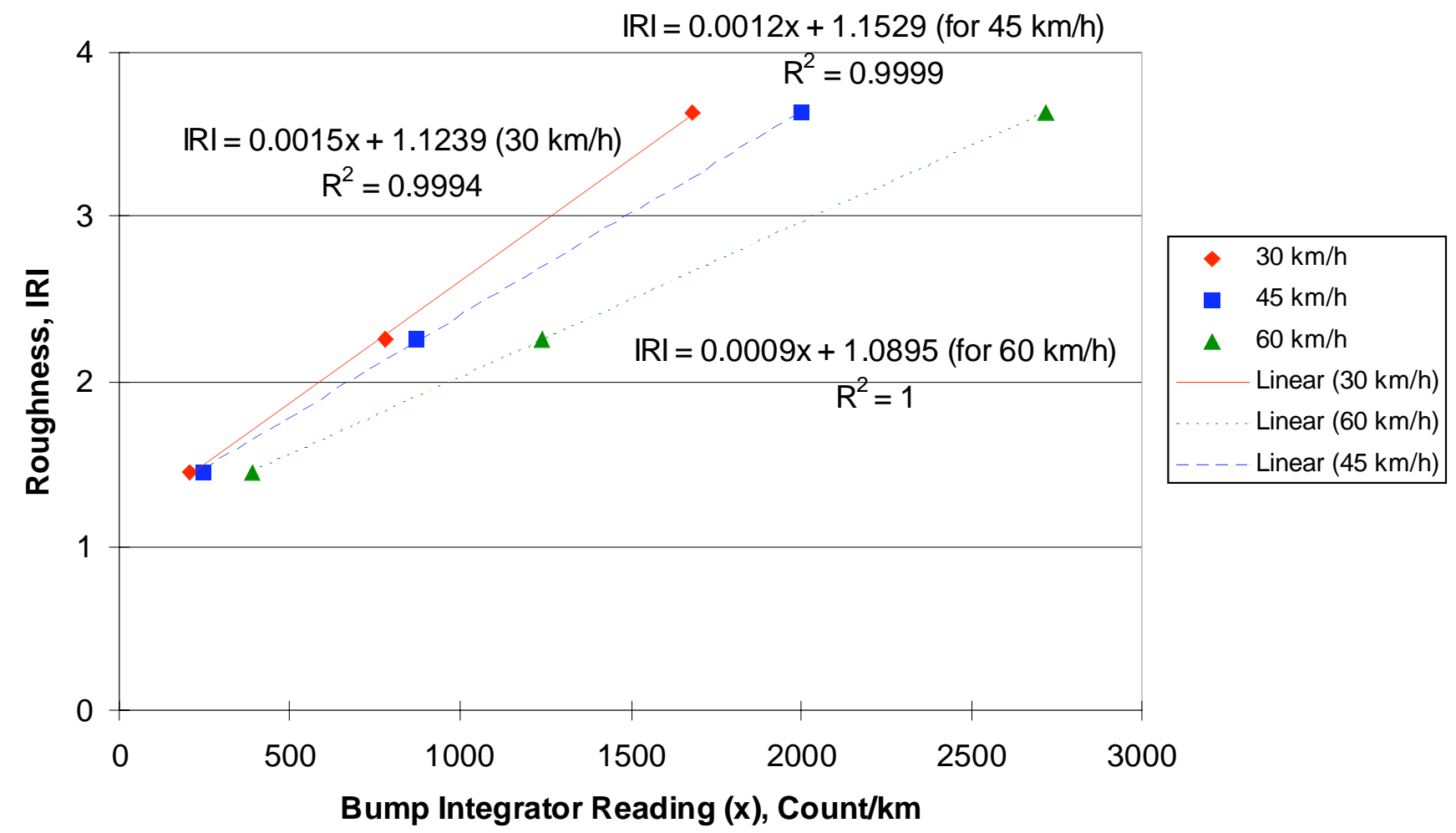

Fig. (3). Roughness Calibration Equation for Bump Integrator 2.

In order to develop the calibration equation of IRI as a function of bump integrator reading and vehicle speed, multiple regression analysis is implemented on the same data used for equations (1), (2), (3), (4), (5) and (6). Observation of the calibration equations (Fig. 3) shows that roughness index increases as bump integrator reading (count $/ \mathrm{km}$ ) increases. On the other hand, higher bump integrator reading (count $/ \mathrm{km}$ ) is found for higher vehicle speed with the same roughness. Therefore, it is clear that a relationship might be developed where IRI would be a function of vehicle speed and bump integrator reading. In order to do so, both intercept and slope coefficient of bump integrator reading is assumed to be functions of vehicle speed which is given below.

$$
\begin{aligned}
\text { IRI } & =\left(\alpha+\beta x_{1}\right)+\left(\delta+\gamma x_{1}\right) x_{2} \\
& =\alpha+\beta x_{1}+\delta x_{2}+\gamma x_{1} x_{2}
\end{aligned}
$$

where, $\mathrm{x}_{1}$ and $\mathrm{x}_{2}$ are vehicle speed and bump integrator reading respectively. $\alpha, \beta, \delta$ and $\gamma$ are constants.

Outcome of multiple regression shows that t-statistic values of $\mathrm{x}_{1}$ are relatively small for both bump integrators. It means $x_{1}$ is not significant in these equations and intercept should not be a function of vehicle speed. Therefore, multiple regression analysis is carried out again eliminating insignificant $\mathrm{x}_{1}$ in the aforementioned equations. It is found that only the slope coefficient of bump integrator reading might be a function of speed. Calibration equation assumed in this analysis is as follows.

$$
\begin{aligned}
\text { IRI } & =\alpha+\left(\delta+\gamma \mathrm{x}_{1}\right) \mathrm{x}_{2} \\
& =\alpha+\delta \mathrm{x}_{2}+\gamma \mathrm{x}_{1} \mathrm{x}_{2}
\end{aligned}
$$

where, $\mathrm{x}_{1}$ and $\mathrm{x}_{2}$ are vehicle speed and bump integrator reading respectively. $\alpha, \delta$ and $\gamma$ are constants.

All the variables in this analysis are found to be significant and the outcome produces the following calibration equations.

$$
\begin{aligned}
& \text { Bump Integrator } 1 \text { : } \\
& \begin{array}{c}
\mathrm{IRI}=1.421+0.0011 * \mathrm{x}_{2}-6.914 * 10^{-6} * \mathrm{x}_{1} \mathrm{x}_{2} \\
\quad(6.064) \quad(7.544)
\end{array} \quad(-3.005) \\
& {\left[\mathrm{R}^{2}=0.7504, \text { Adjusted } \mathrm{R}^{2}=0.7366\right]} \\
& \text { Bump Integrator } 2: \\
& \mathrm{IRI}=1.1344+0.0021 * \mathrm{x}_{2}-1.935 * 10-5 * \mathrm{x}_{1} \mathrm{x}_{2} \\
& \quad(41.829)(41.35) \\
& {\left[\mathrm{R}^{2}=0.9911, \text { Adjusted } \mathrm{R}^{2}=0.9906\right]}
\end{aligned}
$$

Fitness of equation (7) is comparatively lower due to data inconsistency of the left bump integrator as discussed earlier. On the other hand, fitness of equation (8) is very high as equations $(4,5$ and 6$)$ are well fitted. It means, if calibration data is properly collected, good alternative calibration equations (expressions where speed is an explanatory variable) can be generated.

\section{CASE STUDY}

\subsection{Raw Data Collection and Data Processing}

Data collection in this study was carried out in Kagawa prefecture of Japan. Pavement type in this case was asphalt. Total pavement length was $348 \mathrm{~km}$ and roughness data was recorded with a sampling interval of 100 meters by using two bump integrators. Survey speed was tried to be maintained close to $60 \mathrm{~km} / \mathrm{h}$, although it was not possible to 
maintain precisely due to traffic control devices and flows of other vehicles. For data processing, conventional and alternative calibration equations developed in previous section were used which converted bump integrator raw data (count/100 meters) into IRI $(\mathrm{m} / \mathrm{km})$.

\subsection{Results and Discussion}

Roughness indices were determined for sections of various lengths ranging from $1.53 \mathrm{~km}$ to $59.18 \mathrm{~km}$, in this case. There were 18 different sections that made a total length of $348 \mathrm{~km}$. Data were collected with a sampling interval of 100 meters and the calibration equations were used to compute an IRI per 100 meters interval. Finally, an average roughness index (IRI, $\mathrm{m} / \mathrm{km}$ ) was determined over the section. Table 2 summarizes the average IRI for all the 18 sections using conventional and alternative calibration equations. It also shows the percentage difference between IRIs measured by these two calibration equations. Investigation represents that percentage difference is positive in all the 18 sections for both bump integrators. Considering the average of the bump integrators, roughness indices increased by $1.06 \%$ to $7.59 \%$ when alternative calibration equation is applied. If the total pavement length $(348 \mathrm{~km})$ is assumed as one section, roughness values increased by $4.61 \%$ and $2.21 \%$ for bump integrator 1 and bump integrator 2 respectively, when the alternative calibration equation is implemented as shown in Table 3. It means that the conventional calibration equation produces lower roughness value. The most important factor for these differences might be the fluctuations of speed during the actual survey.

\subsection{Causes of Bias and How alternative Method Im- proves the Quality}

Observation of calibration equations, shown in Figs. (2) and (3), indicates that higher speed tends to produce higher bump integrator reading (count $/ \mathrm{km})$ for the same IRI. For instance, in Fig. (3) bump integrator readings for roughness index $3(\mathrm{~m} / \mathrm{km})$ are 1,251 (count $/ \mathrm{km}), 1,539(\mathrm{count} / \mathrm{km})$ and 2,123 (count $/ \mathrm{km}$ ) when vehicle speeds are $30 \mathrm{~km} / \mathrm{h}, 45 \mathrm{~km} / \mathrm{h}$ and $60 \mathrm{~km} / \mathrm{h}$ respectively. On the other hand, ROMDAS processes the bump integrator reading (count $/ \mathrm{km}$ ) and converts it into IRI, using three calibration equations developed for $30 \mathrm{~km} / \mathrm{h}, 45 \mathrm{~km} / \mathrm{h}$ and $60 \mathrm{~km} / \mathrm{h}$. Elaborately, ROMDAS uses calibration equations of $30 \mathrm{~km} / \mathrm{h}, 45 \mathrm{~km} / \mathrm{h}$ and $60 \mathrm{~km} / \mathrm{h}$ for speed ranges 0 to $37.5 \mathrm{~km} / \mathrm{h}, 37.5 \mathrm{~km} / \mathrm{h}$ to $52.5 \mathrm{~km} / \mathrm{h}$ and $52.5 \mathrm{~km} / \mathrm{h}$ to above respectively. Same equation is used for a wide range of vehicle speed. If survey is carried out at a speed of $30 \mathrm{~km} / \mathrm{h}$ and bump integrator generates 1,000 count $/ \mathrm{km}$ in a given section, ROMDAS will apply equation (4) for the right bump integrator. Therefore, it will produce an IRI of $2.62 \mathrm{~m} / \mathrm{km}$. This roughness can be considered as the true roughness of the road section, as survey speed is equal to the calibration speed. If survey speed is $20 \mathrm{~m} / \mathrm{km}$, it should produce a bump integrator reading lower than 1,000, as higher speed tends to produce higher bump integrator

Table 2. Roughness Data for All Individual Sections Using Two Different Calibration Equations

\begin{tabular}{|c|c|c|c|c|c|c|c|c|c|c|c|}
\hline Section & $\begin{array}{c}\text { Length } \\
(\mathbf{k m})\end{array}$ & $\frac{\text { Avg. Speed }}{\text { Km/h }}$ & \multicolumn{3}{|c|}{ Bump Integrator 1} & \multicolumn{3}{|c|}{ Bump Integrator 2} & \multicolumn{3}{|c|}{ Average Roughness } \\
\hline 2 & 47.32 & 46.26 & 2.6 & 2.75 & 5.77 & 2.02 & 2.07 & 2.48 & 2.31 & 2.41 & 4.33 \\
\hline 3 & 46.97 & 44.29 & 2.73 & 2.87 & 5.13 & 2.1 & 2.13 & 1.43 & 2.42 & 2.5 & 3.31 \\
\hline 5 & 39.62 & 49.69 & 2.85 & 2.95 & 3.51 & 2.19 & 2.26 & 3.20 & 2.52 & 2.59 & 2.78 \\
\hline 6 & 31.27 & 48.68 & 2.98 & 3.06 & 2.68 & 2.27 & 2.29 & 0.88 & 2.62 & 2.68 & 2.29 \\
\hline 7 & 27.74 & 52.06 & 2.61 & 2.74 & 4.98 & 2.15 & 2.18 & 1.40 & 2.38 & 2.46 & 3.36 \\
\hline 8 & 9.92 & 52.00 & 2.27 & 2.42 & 6.61 & 1.86 & 1.86 & 0.00 & 2.06 & 2.14 & 3.88 \\
\hline 12 & 2.80 & 41.93 & 2.65 & 2.83 & 6.79 & 2.17 & 2.24 & 3.23 & 2.41 & 2.54 & 5.39 \\
\hline 13 & 2.80 & 46.84 & 2.67 & 2.82 & 5.62 & 2.12 & 2.16 & 1.89 & 2.4 & 2.49 & 3.75 \\
\hline 14 & 2.19 & 55.28 & 2.61 & 2.75 & 5.36 & 2.06 & 2.13 & 3.40 & 2.33 & 2.44 & 4.72 \\
\hline 15 & 2.19 & 46.22 & 3.11 & 3.23 & 3.86 & 2.36 & 2.41 & 2.12 & 2.74 & 2.82 & 2.92 \\
\hline 16 & 2.12 & 47.53 & 5.32 & 5.37 & 0.94 & 4.71 & 4.83 & 2.55 & 5.01 & 5.1 & 1.80 \\
\hline 17 & 1.62 & 24.29 & 3.25 & 3.53 & 8.62 & 2.81 & 2.98 & 6.05 & 3.03 & 3.26 & 7.59 \\
\hline 18 & 1.53 & 26.14 & 3.29 & 3.55 & 7.90 & 3.1 & 3.19 & 2.90 & 3.2 & 3.37 & 5.31 \\
\hline
\end{tabular}

Note: IRI $_{\mathrm{a}}=$ IRI measured by Alternative Calibration Equation; IRI $=$ IRI measured by Conventional Calibration Equation; \% Difference $=\left(\right.$ IRI $\left._{\mathrm{a}}-\mathrm{IRI}_{\mathrm{c}}\right) * 100 / \mathrm{IRI} ;$ Average Roughness $=$ Average of IRIs measured by bump integrators 1 and 2 . 
Table 3. Average IRI of the Whole Network

\begin{tabular}{|c|c|c|c|}
\hline & $\mathbf{I R I}_{\mathrm{c}}$ & $\mathbf{I R I}_{\mathbf{a}}$ & Difference $(\%),\left(\right.$ IRI $\left._{\mathrm{a}}-\mathrm{IRI}_{\mathrm{c}}\right) * 100 / \mathrm{IRI}_{\mathrm{c}}$ \\
\hline Bump Integrator 1 (Left) & 2.82 & 2.95 & 4.61 \\
\hline Bump Integrator 2 (Right) & 2.26 & 2.31 & 2.21 \\
\hline
\end{tabular}

reading. But, ROMDAS will also apply equation (4) for the speed of $20 \mathrm{~km} / \mathrm{h}$. Consequently, it will produce an IRI lower than $2.62 \mathrm{~m} / \mathrm{km}$. In this way the IRI produced is underestimated when survey speed is lower than the calibration speed. Similarly, overestimation exists when survey speed is higher than the calibration speed. Therefore, more calibration equations would produce more accurate values, and in order to eliminate this error infinite numbers of equations are needed if constant speed is not maintained. Alternative calibration equation developed in this study processes raw data using calibration equation, where IRI is a function of both bump integrator reading and vehicle speed. This equation tries to eliminate the bias.

A comparative study between conventional and alternative calibration equations has been carried out using the collected data to make the aforementioned discussion clear. As fitness of the calibration equation of bump integrator 2 is higher, it is used to compare both calibration equations. Figs. (4-6) show the comparison between the roughness indices measured by bump integrator 2 , using conventional and alternative calibration equations. Each point of these figures represents roughness difference for every 100 meters interval. Vehicle speed fluctuates in this study from $0.6 \mathrm{~km} / \mathrm{h}$ to $82.8 \mathrm{~km} / \mathrm{h}$. Data are sorted and divided into three groups according to the vehicle speeds, 0 to $37.5 \mathrm{~km} / \mathrm{h}, 37.5 \mathrm{~km} / \mathrm{h}$ to $52.5 \mathrm{~km} / \mathrm{h}$ and $52.5 \mathrm{~km} / \mathrm{h}$ to above. Fig. (4) stands for speed of 0 to $37.5 \mathrm{~km} / \mathrm{h}$. It shows that roughness indices measured by the alternative calibration equation for the speed close to
$0 \mathrm{~km} / \mathrm{h}$ are about $20 \%$ higher than that of conventional calibration equation. The difference in roughness indices decreases with the increase of vehicle speed. Roughness indices measured near the vehicle speed of $30 \mathrm{~km} / \mathrm{h}$ are almost the same for both equations. On the other hand, IRIs measured by the alternative calibration equations are lower than that of conventional calibration equation for the speed greater than $30 \mathrm{~km} / \mathrm{h}$. In $30 \mathrm{~km} / \mathrm{h}$, conventional calibration equation produces true IRIs as bump integrator was calibrated in this speed. Since, IRIs measured by the conventional and alternative equations are almost the same in this speed, it can be said that alternative calibration equation produces an IRI close to the true roughness. Therefore, this observation shows that IRI measured by the conventional calibration equation is underestimated when speed is less than calibration speed $(30 \mathrm{~km} / \mathrm{h})$ and overestimated when speed is greater than that.

Figs. (5) and (6) stand for vehicle speed of $37.5 \mathrm{~km} / \mathrm{h}$ to $52.5 \mathrm{~km} / \mathrm{h}$ and $52.5 \mathrm{~km} / \mathrm{h}$ to above respectively. In these figures, roughness values are also underestimated by the conventional calibration equation when vehicle speeds are 37.5 $\mathrm{km} / \mathrm{h}$ to $45 \mathrm{~km} / \mathrm{h}$ and $52.5 \mathrm{~km} / \mathrm{h}$ to $60 \mathrm{~km}$. On the other hand, roughness indices are overestimated when speeds are 45 $\mathrm{km} / \mathrm{h}$ to $52.5 \mathrm{~km} / \mathrm{h}$ and $60 \mathrm{~km} / \mathrm{h}$ to above. In all the three cases, it was indicated that roughness values measured by both methods are almost the same when vehicle speeds are close to the calibration speeds; $30 \mathrm{~km} / \mathrm{h}, 45 \mathrm{~km} / \mathrm{h}$ and 60 $\mathrm{km} / \mathrm{h}$. Regression analyses (Figs. 4-6) produce following

Speed 0 to $37.5 \mathrm{~km} / \mathrm{h}$

(Bump Integrator 2)

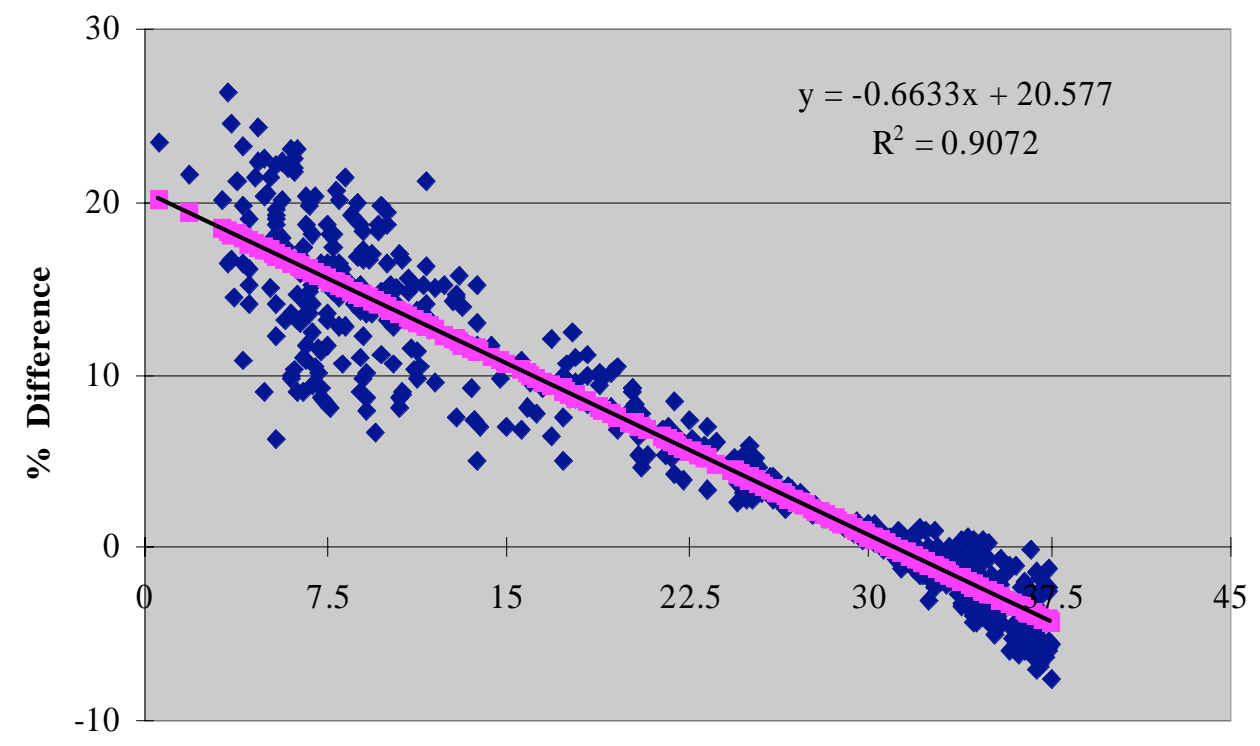

Speed $(\mathbf{k m} / \mathbf{h})$

Fig. (4). Comparison for Vehicle Speed of 0 to $37.5 \mathrm{~km} / \mathrm{h}$. 
Speed $37.5 \mathrm{~km} / \mathrm{h}$ to $52.5 \mathrm{~km} / \mathrm{h}$

(Bump Integrator 2)

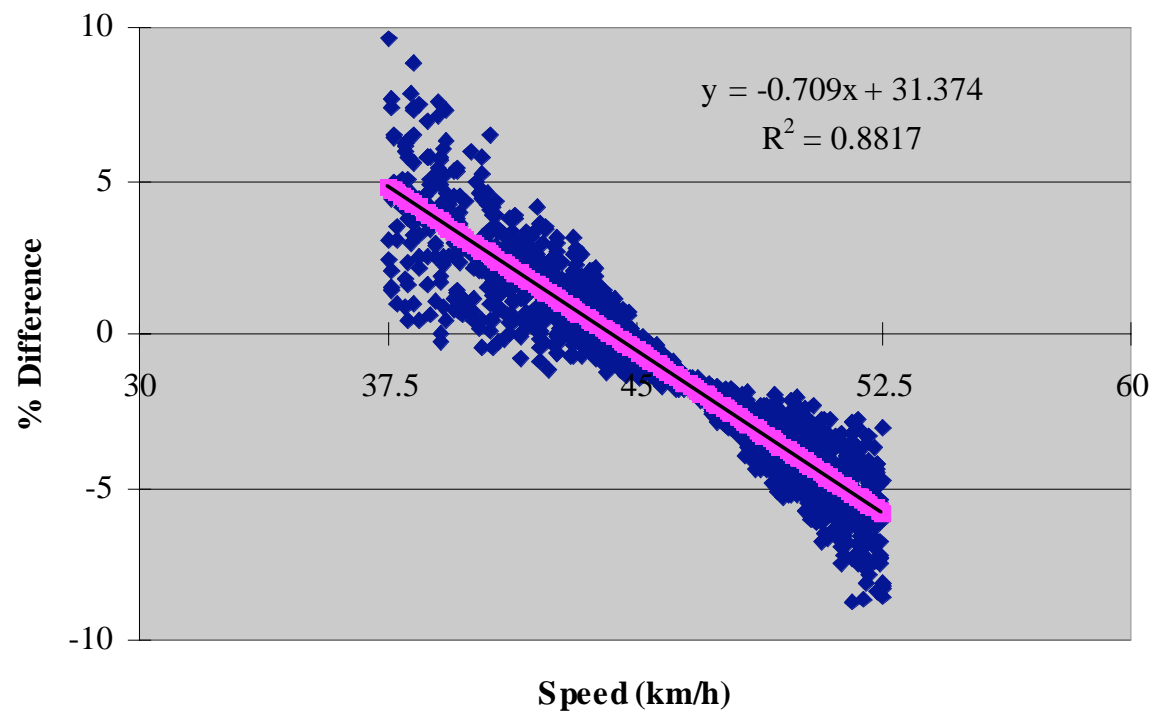

Fig. (5). Comparison for Vehicle Speed of $37.5 \mathrm{~km} / \mathrm{h}$ to $52.5 \mathrm{~km} / \mathrm{h}$.

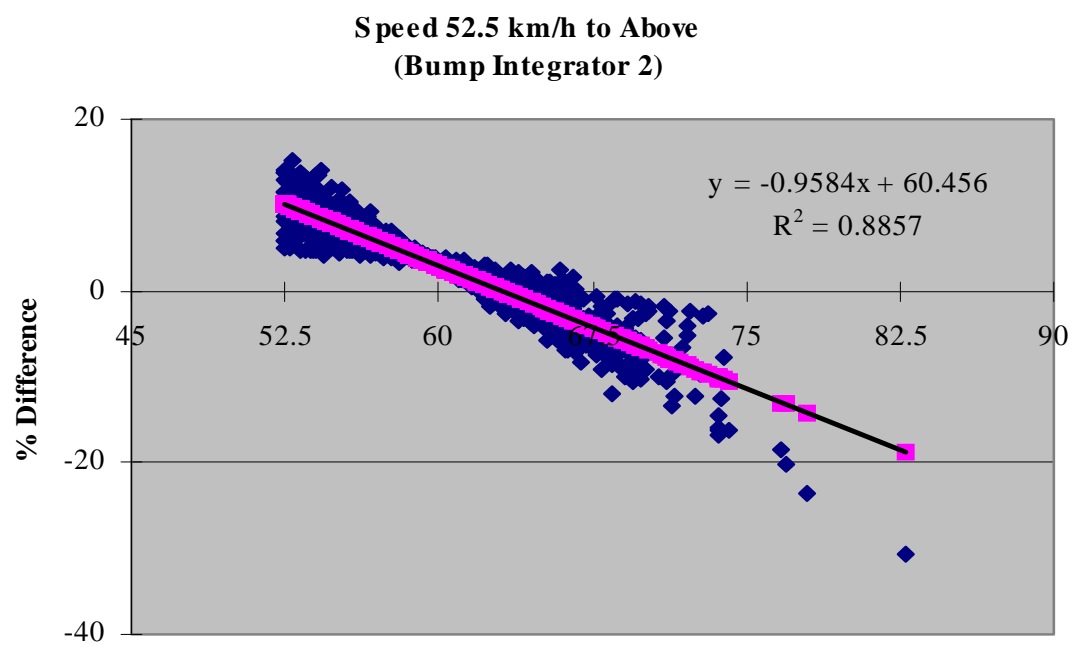

Speed $(\mathbf{k m} / \mathbf{h})$

Fig. (6). Comparison for Vehicle Speed of $52.5 \mathrm{~km} / \mathrm{h}$ to Above.

relationships, predicting the difference between IRIs as a function of survey speed.

For Speed of 0 to $37.5 \mathrm{~km} / \mathrm{h}$ :

$\mathrm{y}=-0.6633 \mathrm{x}+20.577$

$(-75.09) \quad(91.31) \quad$ [Adjusted $\left.\mathrm{R}^{2}=0.91\right]$

For Speed of 37.5 to $52.5 \mathrm{~km} / \mathrm{h}$ :

$\mathrm{y}=-0.709 \mathrm{x}+31.374$

$(-105.76)(100.72) \quad$ [Adjusted $\left.R^{2}=0.88\right]$

For Speed of $52.5 \mathrm{~km} / \mathrm{h}$ to Above:

$\mathrm{y}=-0.9584 \mathrm{x}+60.456$

$(-108.37) \quad(115.74) \quad$ [Adjusted $\left.\mathrm{R}^{2}=0.89\right]$ where $y=\%$ Difference, $x=$ Speed $(\mathrm{km} / \mathrm{h})$

$\%$ Difference $=\left(\right.$ IRI $\left._{\mathrm{a}}-\mathrm{IRI}_{\mathrm{c}}\right) * 100 / \mathrm{IRI}_{\mathrm{c}}$
Numbers in the parentheses are t-statistics of respective parameters.

Equation (9) represents that IRIs differ by $5 \%$ for the speed difference of $7.53 \mathrm{~km} / \mathrm{h}$ when vehicle speed ranges from 0 to $37.5 \mathrm{~km} / \mathrm{h}$. Similarly, $5 \%$ difference in IRIs is found for speed differences of $7.05 \mathrm{~km} / \mathrm{h}$ (10) and $5.22 \mathrm{~km} / \mathrm{h}$ (11) when the speed ranges from $37.5 \mathrm{~km} / \mathrm{h}$ to $52.5 \mathrm{~km} / \mathrm{h}$ and $52.5 \mathrm{~km} / \mathrm{h}$ to above respectively.

The outcome of this comparison supports that IRI measured by conventional calibration equation is underestimated when survey speed is lower than the calibration speed and overestimated when the speed is higher than that. In this study, conventional method produces lower roughness values for all the 18 sections as shown earlier in Table $\mathbf{2}$. Vehicle speeds lower than the calibration speeds are dominating 
in this case which might be the reason of this underestimation. In order to clarify this feature, each of the three speed ranges is divided into two parts according to underestimation and overestimation. Speed range of 0 to $37.5 \mathrm{~km} / \mathrm{h}$ is divided into two groups, lower than $30 \mathrm{~km} / \mathrm{h}$ and greater than 30 $\mathrm{km} / \mathrm{h}$. Similarly, speed ranges of $37.5 \mathrm{~km} / \mathrm{h}$ to $52.5 \mathrm{~km} / \mathrm{h}$ and $52.5 \mathrm{~km} / \mathrm{h}$ to above are classified into four groups, lower than $45 \mathrm{~km} / \mathrm{h}$, greater than $45 \mathrm{~km} / \mathrm{h}$, lower than $60 \mathrm{~km} / \mathrm{h}$ and greater than $60 \mathrm{~km} / \mathrm{h}$. So, there are six groups in total. IRIs measured for these groups are listed in Table 4. Bump integrator 2 exhibits a clear reason for which IRI measured in this study is underestimated using conventional calibration equation. It shows that $33.59 \mathrm{~km}$ road is measured by a speed lower than $30 \mathrm{~km} / \mathrm{h}$. IRIs measured for this pavement are underestimated by $11.03 \%$. On the other hand, $21.57 \mathrm{~km}$ road is measured by a speed of greater than $30 \mathrm{~km} / \mathrm{h}$ and lower than $37.5 \mathrm{~km} / \mathrm{h}$. IRIs are overestimated by $2.68 \%$ for this $21.57 \mathrm{~km}$. Therefore, in the speed range of 0 to 37.5 $\mathrm{km} / \mathrm{h}$, underestimated roughness compensates overestimation and dominates. Similarly, for the speed range of $37.5 \mathrm{~km} / \mathrm{h}$ to $52.5 \mathrm{~km} / \mathrm{h}, 90.43 \mathrm{~km}$ pavement is overestimated (3.53\%) while underestimation $(2.05 \%)$ goes for $53.42 \mathrm{~km}$. Overestimation dominates in this speed range. Finally, for the speed range of $52.5 \mathrm{~km} / \mathrm{h}$ to above, $97.01 \mathrm{~km}$ pavement is underestimated $(7.06 \%)$ and roughness indices are overestimated $(1.62 \%)$ for $50.18 \mathrm{~km}$. Underestimation also dominates in this range. Accumulating all the roughness indices it was found that the underestimation compensates the overestimation and dominates in the conventional calibration equation. It causes the bias in the conventional calibration equation. The magnitude of the underestimation over the whole network can be estimated by (12).

$B=\frac{L_{1} P_{1}+L_{2} P_{2}+\ldots . .+L_{n} P_{n}}{L_{1}+L_{2}+\ldots . .+L_{n}}$

where B is magnitude of bias (underestimation or overestimation), $\mathrm{L}$ is pavement length and $\mathrm{P}$ is underestimation $(\mathrm{P}>0)$ or overestimation $(\mathrm{P}<0)$ in percentage. For the bump integrator 2, B is obtained as $2.04 \%$. It means that IRIs are underestimated by $2.04 \%$ for the whole network.

Similarly, for bump integrator 1, underestimation dominates, although it does not show clear relationship of underestimation and overestimation with vehicle speed. Roughness indices are underestimated by conventional calibration equation for all the speed ranges except the speed range of
$45 \mathrm{~km} / \mathrm{h}$ to $52.5 \mathrm{~km} / \mathrm{h}$. Lower fitness in calibration equation causes this inconsistency which might be improved by having more number of runs during calibration.

\section{CONCLUSION}

Commonly used response type road roughness measuring systems are not free from speed constraint and are not suitable for any survey speed or speed fluctuations. This limitation produces a significant bias in roughness measurement if the survey speed is not properly maintained. In order to tackle this problem, this paper presents a regression relationship of IRI as a function of bump integrator reading and survey speed using ROMDAS.

It is observed in ROMDAS that higher speed produces higher bump integrator reading (count $/ \mathrm{km}$ ) for the same roughness index. Therefore, roughness index measured by conventional calibration equation is underestimated when survey speed is lower than the calibration speed and overestimated when speed is higher than that. If the distribution of speeds is skewed, overestimation or underestimation may dominate causing the bias in roughness measurement. Logically it can be said that more calibration equations would produce more accurate values and in order to eliminate this bias using the conventional calibration equation, infinite number of equations are needed. For this reason, ROMDAS suggests maintaining a constant speed during survey which is cumbersome for the existence of traffic control devices and flows of other vehicles. Alternative calibration equation developed in this study produces calibration equation using bump integrator reading and survey speed as explanatory variables of roughness index. This equation may not be much affected by speed fluctuations during survey as speed a variable in this case. Therefore, it is able to measure roughness more precisely and eliminate potential bias caused by speed fluctuations. Although this paper focuses on ROMDAS for the development of calibration equation of IRI as a function of survey speed, same concept might be applied to other RTRRMSs to reduce the effects of speed variations.

Bump integrator was calibrated using three different sections in this study. To improve the results, more reference sections might be selected. In addition, three speeds (30 $\mathrm{km} / \mathrm{h}, 45 \mathrm{~km} / \mathrm{h}$ and $60 \mathrm{~km} / \mathrm{h}$ ) were used for calibration. Increasing the number of speeds is also recommended for better findings. Moreover, magnitude of the bias produced by conventional approach was measured with respect to IRIs

Table 4. IRI Measured for Different Speed Ranges

\begin{tabular}{|c|c|c|c|c|c|c|c|}
\hline $\begin{array}{c}\text { Speed Ranges } \\
(\mathbf{k m} / \mathbf{h})\end{array}$ & $\begin{array}{c}\text { Length } \\
(\mathrm{km})\end{array}$ & IRI $_{c}$ & IRI $_{a}$ & $\%$ Difference & IRI $_{c}$ & IRI $_{a}$ & $\%$ Difference \\
\hline $30<$ Speed $<37.5$ & 21.57 & 3.12 & 3.26 & 4.37 & 2.70 & 2.62 & -2.68 \\
\hline $37.5<$ Speed $<45$ & 53.42 & 2.96 & 2.98 & 0.81 & 2.26 & 2.30 & 2.05 \\
\hline $52.5<$ Speed $<60$ & 97.01 & 2.58 & 2.87 & 11.15 & 2.05 & 2.19 & 7.06 \\
\hline Speed $>60$ & 50.18 & 2.77 & 2.96 & 7.02 & 2.17 & 2.13 & -1.62 \\
\hline
\end{tabular}

Note: $\mathrm{IRI}_{\mathrm{a}}=\mathrm{IRI}$ measured by Alternative Calibration Equation; IRI $\mathrm{I}_{\mathrm{c}}=\mathrm{IRI}$ measured by Conventional Calibration Equation; \% Difference $=\left(\mathrm{IRI}_{\mathrm{a}}-\mathrm{IRI}_{\mathrm{c}}\right)^{*} 100 / \mathrm{IRI}_{\mathrm{c}}$. 
$\left(\right.$ IRI $\left._{a}\right)$ measured by alternative calibration equation. It was shown that $\mathrm{IRI}_{\mathrm{a}}$ is close to the true roughness. If calibration equations are developed using a large number of vehicle speeds, more accurate IRI $_{a}$ might be obtained. However, it would be better if other methods or measuring devices such as Class I and Class II can be used to evaluate the accuracy of $\mathrm{IRI}_{\mathrm{a}}$. Future studies can focus on this issue.

\section{REFERENCES}

[1] C. R. Bennett, A. Chamorro, C. Chen, H. D. Solminihac and G. W. Flintsch, Data Collection Technologies for Road Management, Version-2. East Asia Pacific Transport Unit, The World Bank: Washington, D.C., 2007.

[2] J. Budras, A Synopsis on the Current Equipment Used for Measuring Pavement Smoothness, Federal Highway Administration: USA, 2001.

[3] R. S. Archondo-Callao, Unpaved Road Roughness Estimation by Subjective Evaluation, Infrastructure Note, Transport, Water and Urban Development, The World Bank: USA, 1999.

[4] R. Haas, W. R. Hudson and J. Zaniewski, Modern Pavement Management, Krieger Publishing Company, Krieger Drive, Malabar: Florida, 1994.

[5] R. Robinson, U. Danielson and M. Snaith, Road Maintenance Management, PALGRAVE: New York, 1998.

[6] PIARC, Highway Development and Management Model, Version 1.3, International Study of Highway Development and Management (ISOHDM), World Road Association, PIARC, Paris: France, 2003.

[7] T. Watanatada, C. G. Harral, W. D. O. Paterson, A. M. Dhareshwar, A. Bhandari and K. Tsunokawa, The Highway Design and Maintenance Standards Model, Description of the HDM-III Model. The World Bank: Washington, D.C., vol. 1, 1987.

[8] K. Tsunokawa and J. L. Schofer, "Trend curve optimal control model for highway pavement maintenance: case study and evaluation", Transport. Res. A., vol. 28, no. 2, pp. 151-166, 1994.

[9] K. Tsunokawa, D. V. Hiep and R. Ul-Islam, "True Optimization of Pavement Maintenance Options with What-If Models", Comput. Aided. Civ. Infrastruct. Eng., vol. 21, pp. 193-204, January 2006.
[10] Y. Li and S. Madanat, "A Steady-state solution for the optimal pavement resurfacing problem", Transport. Res. A., vol. 36, pp. 525-535, 2002

[11] Y. Ouyang and S. Madanat, "Optimal scheduling of rehabilitation activities for multiple pavement facilities: exact and approximate solutions", Transport. Res. A., vol. 38, issue 5, pp. 347-365, 2004.

[12] Y. Ouyang and S. Madanat, "An analytical solution for the finitehorizon pavement resurfacing planning problem", Transport. Res. B., vol. 40, Issue 9, pp. 767-778, 2006.

[13] M. W. Sayers, T. Gillespie and W. D. O. Paterson, Guideline for Calibrating Road Roughness Measurements, World Bank Technical Report 46, The World Bank: Washington D.C., 1986.

[14] C. R. Bennett, A. Chamorro, C. Chen, H. D. Solminihac and G. W. Flintsch, Data Collection Technologies for Road Management, East Asia Pacific Transport Unit, The World Bank: Washington D.C., 2005.

[15] M. A. Cundill, The MERLIN Road Roughness Machine: User Guide, Transport Research Laboratory Report 229, 1996.

[16] D. Widayat, A. J. Adhitya and T. Toole, Roughness calibration studies using different measuring systems, Overseas Centre: Transport Research Laboratory, November 1990.

[17] J. C. Young, Calibration, maintenance and use of the rolling straightedge, Supplementary Report 290: Transportation Research Laboratory, 1977.

[18] P. K. Hunter and H. A. Porter, ROMDAS for Windows User's Guide. Data Collection Limited, Motueka 7161: New Zealand, 2005.

[19] Roadmaster-IRI Tester. Al-engineering Oy. [Online] Available: http://www.al-engineering.fi/en/roadmaster.html. [Accessed July 04, 2006].

[20] Roughometer II, ARRB Technology, ARRB Group Limited, Australia. [Online] Available: http://www.arrb.com.au/documents/PBRoughometerII.pdf. [Accessed July 03, 2006].

[21] C. R. Bennett, "Testing of ROMDAS Bump Integrator". [Online] Available: http://www.romdas.com/romdascd/info/working/bi1.pdf. [Access July 04, 2006]

[22] Bump Integrator Specification Sheet, ROMDAS. [Online] Available: http://www.romdas.com/romdascd/info/specs/bi.pdf. [Accessed March 22, 2006]

[23] P. K. Hunter and H. A. Porter, "Z-250 Reference Profiler User's Guide," Data Collection Limited, Motueka 7161: New Zealand, 2005.

(C) Rashid and Tsunokawa; Licensee Bentham Open.

This is an open access article licensed under the terms of the Creative Commons Attribution Non-Commercial License (http://creativecommons.org/licenses/by$\mathrm{nc} / 3.0 /$ ) which permits unrestricted, non-commercial use, distribution and reproduction in any medium, provided the work is properly cited. 